\title{
14 undeRstaNDING E-COMMERCE THROUGH GENRE THEORY: THE CASE OF THE CAR-BUYING PROCESS
}

\author{
Sue Conger \\ Ulrike Schultze ${ }^{1}$ \\ Southern Methodist University \\ U.S.A.
}

\begin{abstract}
There is a dearth of theory-based guidance for organizations making decisions about electronic commerce and about enhancing their business processes through the use of new media, particularly the World Wide Web (Web). Genre theory provides a useful scaffold for generating such guidance. Communication genres are generic responses to recurring situations. Examples include a business letter, a meeting or a memo (Yates and Orlikowski 1992). In this paper, we apply genre theory to evaluate the business processes involved in buying a car. From this analysis, we hypothesize changes in the business process and in buyer/seller satisfaction that result from electronically mediated genre of communication.
\end{abstract}

Keywords: Gene theory, automotive industry, electronic commerce, communications, richness theory, car buying process.

\section{Introduction}

More and more organizations are engaging in electronic commerce to cut costs and stay competitive (Girishankar 1998). Furthermore, some services that did not exist previously now form the basis of viable on-line or "virtual" businesses. In many cases,

${ }^{1}$ Authors' names are in alphabetical order. Both contributed equally to the ideas presented in this paper. 
however, migrating business processes to the Web has not resulted in the kind of business success that some predicted. For instance, Amazon.com is still not profitable despite a phenomenal growth in sales during $1998 .{ }^{2}$ The airlines are trying to entice customers with incentives for electronically-booked flights (e.g., Travelocity, Delta).

Genre theory is useful in explaining the mixed success of e-commerce because it provides a scaffold for thinking through the implications of adding new media to the existing media repertoire. Generic communicative responses, or genres, develop in response to events that recur in a situated social setting (Orlikow'ski and Yates 1994). For instance, a letter of recommendation is a response to a potential employer's desire to hear a previous employer's evaluation of a candidate. A letter of recommendation represents a genre recognizable primarily by its purpose, i.e., the socially constructed understanding of the intent, content and expected use of the communication (Miller 1984). There are other genres, such as an e-mail, that are primarily recognizable by their form. Form is an amalgamation of structure, medium, and language (Yates and Orlikowski 1992).

In this paper we integrate genre theory with business process thinking to explore the impact of the Web on the car buying process. The car buying process is a series of communicative acts which are accomplished through a genre system, i.e., a set of interrelated genres that interact with each other in specific settings (Brazerman 1995). We have chosen the car industry because of the attention it has received with respect to e-commerce (Kichen 1997). Furthermore, the car industry is one of the largest (20 million units a year) and one of the most studied (Llosa and Lee 1998).

Because buying a new car is a substantial purchase and thus a significant decision for most people; the car buying process is somewhat stressful, requiring deliberate and "mindful" information processing (Kichen 1997). For many customers, especially women, it is an also an unpleasant experience because many sales associates assume that they know nothing about cars and treat them with condescension (Chisholm 1999; Mahoney 1991; Prochazka-Dahl 1997). Furthermore, the used-car-salesman stereotype, that is, a "car guy with a beer gut and greased back hair, wearing polyester pants and a plaid jacket" "who is ready to sell unsuspecting customers a "lemon," negatively impacts car sales associates in general. The disintermediation of Web technology and the provision of vast amounts of information should have a positive effect on car buyers in general, and women car buyers in particular (www.womanmotorist.com).

Recent statistics show that about $20 \%$ of new car buyers, about four million per year, now research their purchases on the Web (Black Enterprise). As this number grows, changes in the car purchase process are becoming clear. Genre theory provides the lens for exploring those changes and drawing conclusions with both theoretical and practical value.

Five steps, or communicative acts, comprise the car buying process. These are (1) information gathering, (2) test driving, (3) qualifying the buyer, (4) negotiating the price, and (5) finalizing the deal. For each communicative act, we explore three broad

${ }^{2}$ In 1998, Amazon.com posted book sales of $\$ 610$ million; a 313\% increase over 1997 sales (New York Times Magazine, 3/14/1999).

\footnotetext{
${ }^{3}$ Paraphrased from an interview with a regional retail development manager at a large U.S. car manufacturer (4/1/1999).
} 
categories of genre-face-to-face, paper-based, and Web-enabled. We include e-mail, web pages and electronic discussions in our Web-enabled category. While our three genre categories may be an oversimplification, this level of analysis allows us to develop a coherent set of hypotheses about an entire business process. We ask questions like: What happens when the communicative act of price negotiation becomes computermediated? How does each communicative act change? How is the sales/buying process as a whole affected? What do these changes mean for buyer and sales associate satisfaction?

Our discussion proceeds as follows. We outline genre theory and develop a theoretical framework that integrates genre theory with business process thinking. Then we turn our attention to the automotive industry, and describe the new car sales process in terms of its communicative acts. For each communicative act, we explore the different genres and hypothesize what impact Web-enabled genres will have on the car buying process, particularly with respect to such outcome variables as cost, customer satisfaction, sales associate satisfaction, and the time it takes to close a sale.

\section{Genre Theory}

Genre is a concept derived from literary theory that distinguishes different forms of literature, including the poem, the drama, the tragedy, the comedy, and the novel (Abrams 1988). Recently, the concept of genre has been expanded to describe business communications, such as the business letter, the memo, and the e-mail message (Orlikowski and Yates 1994; Yates and Orlikowski 1992). Genre is generally defined in terms of content and form, which are further broken down into the following features:

- Substance: the purpose and content of the communication, e.g., a question.

- Structure: the format in which information is presented, e.g., the "fill-in-theblank" form.

- Media: the medium through which the communication occurs, e.g., face-to-face or electronically mediated.

- Language: the type of expression used in the communication, e.g., jargon or formal language.

These features of genre are highly interdependent and dynamically intertwined (see Figure 1), implying that a change in one genre element will cause a ripple effect through the other elements. The work by Orlikowski and Yates (1994) on the development of the e-mail genre from the business letter illustrates the events that trigger genre changes and the kinds of adjustments made in genre elements to accommodate social and technological changes.

Shepherd and Watters (1999) argue that the use of the computer and the Internet has made it necessary to extend the definition of genre as a combination of content and form. They propose a new class of genre, namely, "cybergenre," which is defined in terms of content, form, and functionality. Functionality refers to the capability of the new medium, e.g., interactivity through search engines.

Since our objective in this research is to hypothesize the impact of "cybergenres" on the car buying process, we need to compare these new genres with existing ones. We therefore apply Orlikowki and Yates' more generic definition of genre. 


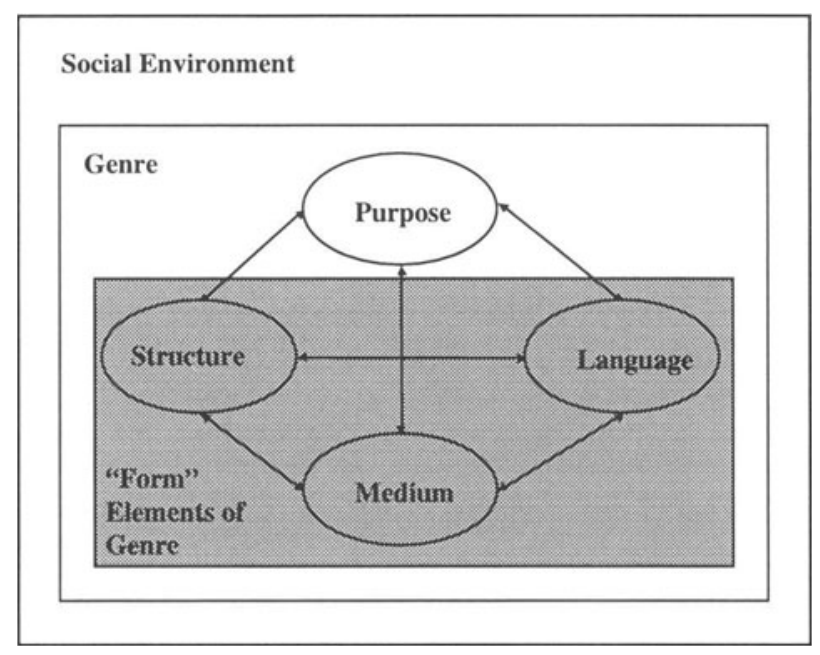

\section{Figure 1. Dynamic Relationship between the Features of Genre}

In this paper, we focus on the effect of a technology-induced medium shift on the communicative acts that compose the new car buying process. Media channels embody specific features such as anonymity and asynchronicity (Griffith and Northcraft 1994). Through the identification of these features and the tracing of their implications for the four genre elements, we explore the effect of a new medium on each communicative act independently and on the overall business process.

\subsection{Theoretical Framework: Business Processes as Genre Systems}

By providing the theoretical scaffold for tracing the ripple effects of a medium change through the other genre elements to a change in communicative and, ultimately, social practice, genre theory is a powerful tool for analyzing the implications of introducing new media into a business process. Business processes are a series of communicative acts that can be accomplished through a variety of socially recognizable responses, i.e., genres. Depending on personal preferences and contextual circumstances, a specific genre or set of genres can be selected to achieve a communicative act. The relationship of business processes to genres is depicted in Figure 2.

With this framework, we can generate hypotheses about the implications of adding a new medium to the mix of genres that make up a genre system. It is through such a genre system that a business process is accomplished. When a new medium, such as electronic communication via the Web, becomes a viable alternative to the existing media, we would expect a new category of genres to develop (i.e., a new horizontal band in Figure 2). Since the genres that are available to accomplish one communicative act 


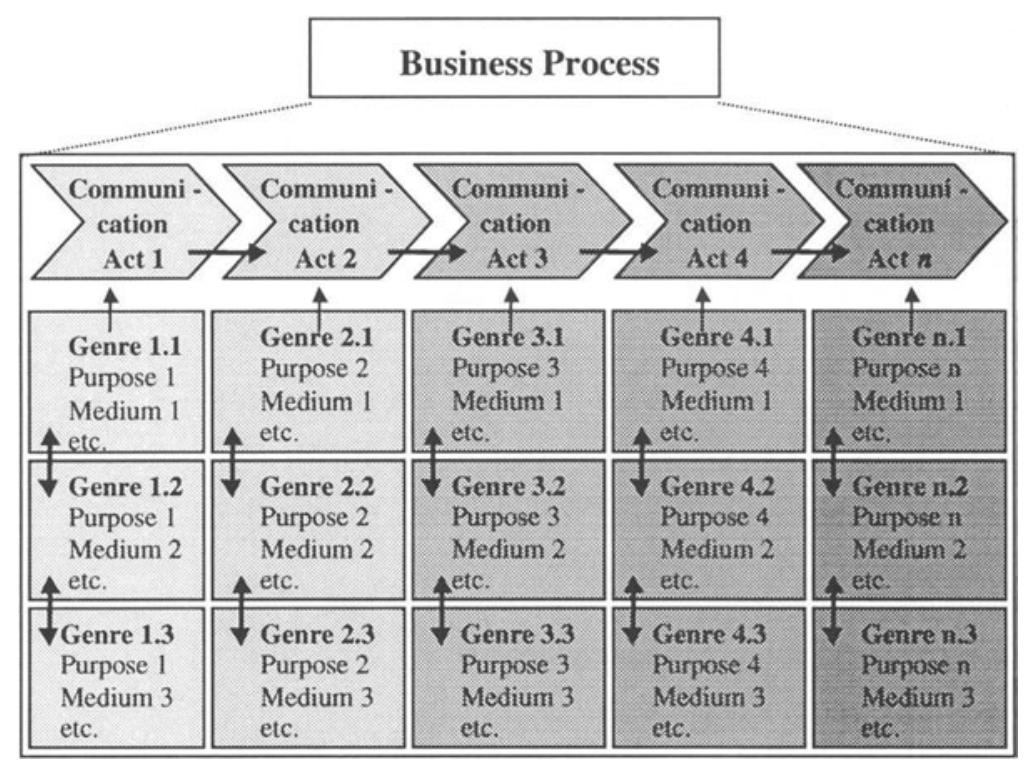

Figure 2. Business Process as a Genre System

in the business process are intertwined, the new Web-enabled genres ${ }^{4}$ will induce changes in the genres belonging to the other genre categories (e.g., face-to-face and paper-mediated genres.) In Figure 2, these changes are depicted by arrows. The consequences of a new medium on both individual communicative acts and the business process as a whole are largely dependent on the features embodied in the medium (Griffith and Northcraft 1994). In genre theory, these media features find expression in the structure element. In the next section, we apply the model to the business process of buying a new car.

\section{The Business Process of Buying a New Car}

The car buying process includes the following communicative acts:

- information gathering: a communicative act in which car buyers are informed of their alternatives and narrow their purchasing choices;

- test drive (or tryout): a communicative act in which the car buyer interacts with the car directly;

- qualification of a buyer: a communicative act in which the sales person seeks to determine the buyer's willingness and ability to pay for the intended purchase;

${ }^{4}$ Shepherd and Watters (1999) identify the following Web-enabled genres: home page, brochure, resource, catalogue, search engine and game. Crowston and Williams (1999) define FAQs as a Web-enabled genre. 
- negotiation of price: a communicative act in which the car deal is structured with respect to trade-ins and discounts, as well as financing; and

- finalization of sale: a communicative act in which payment is made and physical goods such as title documents, keys and cars are exchanged.

These communicative acts can overlap and occur simultaneously. For instance, the test drive may coincide with buyer qualification. We will now examine each of the communicative acts in turn to establish which communication genres apply to them and how Web-enabled genres affect them.

\subsection{Information Gathering}

The purpose of information gathering is for car manufacturers, dealers and other agencies to influence the customer's purchasing decision with respect to the make, model, and year of the car, as well as the choice of dealership with whom the customer will do business. For the buyers, the purpose of information gathering is to gain an understanding of the car market and to narrow their purchasing alternatives. The content of genres used for information gathering includes primarily the features, functions, pricing and options of the car, as well as assessments of the car. Appendix A lists examples of genres as well as the structural and language components that have developed in response to buyers' recurring information gathering needs.

A large number of communication genres have developed in response to the needs of dealers and manufacturers to influence the buyer's purchasing behavior as well as buyers' need to develop an understanding of car offerings. Manufacturers' and dealers' advertisements represent an advocacy-based informing strategy. Independent evaluations of cars range from the objective, such as Consumer Reports, to the carenthusiast, such as Car and Driver, which represent a comparison-based informing strategy. These genres are instantiated across the three media groups used in this analysis. There are also several Web-enabled genres that are less focused. Bulletin boards, online discussion groups, and e-mails between correspondents also contain anecdotes and other informal information about cars.

It is in the structure aspect of genres that we see most of the differences between the three genre categories. Paper-based information gathering genres provide noninteractive, one-way, asynchronous communication between presenter and reader. The reader/buyer is unidentifiable and, therefore, the information presented is not customized to the buyer's needs or preferences. Information is distributed through many channels, including library, bookstore, and news agents.

Face-to-face information gathering communications are fully interactive, real-time, synchronous, and bi-directional between a sales associate and buyer. The buyer is thus known to the sales associate and information can be tailored to the buyer's requests and perceived needs. Typically, geographic proximity limits the variety of accessible information sources (e.g., sales associates.)

Web-enabled information gathering exhibits limited interactivity. Even though most Web pages afford only one-way communication, search capabilities provide buyers with more direct access to requested information. This potential for interactivity as well as the reduced need for space conservation (which is an especially challenging problem in print media), makes it possible for information providers to make more extensive and 
detailed information available to buyers. The electronic nature of the medium also reduces the cost of editing the information. This implies that buyers using Web-enabled genres have access to more accurate and up-to-date information than they do in printmediated genres and more permanent access to information than they do in the genres mediated by face-to-face interactions. The degree to which the information is customized to buyers' needs and preferences in web-enabled genres depends on the specific genre they use and on whether they choose to be identified. For instance, in a car features site like www.edmunds.com the information is not customized and the buyer remains unidentified. However, if the car buyer were to e-mail a sales associate or a friend, they would be identified and the information gathered would likely be specific to the buyer's needs and preferences.

Finally, the language differs for each genre category, ranging from the formal and explicit in print media genres to the more informal and non-verbal in genres based on face-to-face interactions. In Web-mediated genres, the language is primarily formal and explicit into which are mixed many affective, non-verbal language elements (i.e., multimedia including graphics, photographs, audio and video). This suggests that webenabled genres support rich communication (Daft and Lengel 1986).

Based on the differences between the genre elements of the face-to-face, papermediated and Web-enabled genre categories, we expect to see a number of changes in the information gathering stage of the car buying process as more and more buyers rely on Web-enabled genres (e.g., dealer and manufacturer Web sites and e-mail interactions with sales associates). First, Web-enabled genres will reduces the cost of information gathering for the buyer. In part, this is due to the asynchronous nature of the Webenabled genres. Asynchronicity reduces the coordination costs that are typically incurred in face-to-face environments (Kambil and van Heck 1998). The cost savings to the buyer can further be attributed to the fact that buyers can access multiple sources of information through one channel, that is, the computer. This saves travel costs related to obtaining print media from bookstores and libraries, for instance. The time spent gathering information should be reduced when Web-enabled genres are used because these genres support some degree of interactivity, e.g., search facilities reduce the time it takes to locate specific pieces of information.

Second, because the cost of information gathering is lower for electronic media, buyers, per period of time, will be able to gather larger amounts and a greater variety of information than they would if they had relied on face-to-face or paper-mediated genres (Kanell 1998, Kichen 1997). Because car purchases are infrequent and substantial enough for consumers to value information highly (Dunnan 1998), we expect that the car buyers will spend the same amount of time gathering information irrespective of medium.

Third, buyer satisfaction with the information gathering genre is a function of time, cost, perceived value and availability of information. Buyer satisfaction should increase with the use of Web-enabled genres because of lower costs and greater information availability. With the increase of information, buyers will feel more informed and more confident and satisfied with their decisions (O'Reilley 1980).

Furthermore, buyers' ability to choose whether they want to be identified by the information providers during their information gathering activities is also expected to increase buyers' satisfaction. The anonymity of electronic media should be particularly relevant to women who generally dislike dealing with a car sales associate because of 
the condescending attitudes that male sales associates display toward them (Chisholm 1999, Prochazka-Dahl 1997). Web-enabled information gathering proceeds in an impersonal buyer-paced context, in which the buyer remains unidentified and less exposed to pressures pushing him/her into a premature purchasing decision. Thus, anonymity and asynchronicity, both of which are structural features of Web-enabled genres, are expected to contribute to higher buyer satisfaction (Kichen 1997).

Fourth, with the increased use of Web-enabled genres on the part of buyers, the sales associate's job of influencing a buyer's behavior becomes more difficult. Consequently, the sales associate's satisfaction with the information gathering stage of the car buying process is expected to decline. In part, this is because influencing an informed buyer is more difficult than influencing an uninformed buyer given that the latter has little or no basis for assessing the validity of the sales associate's claims. Furthermore, the more informed buyer is likely to be the buyer that already mistrusts car sales associates.

Another challenge for the sales associate lies in influencing a misinformed buyer. Buyers relying on Web-enabled genres are likely to feel highly informed (given the supposed accuracy and up-to-date nature of the information available through the $\mathrm{Web}^{5}$ ), and therefore particularly suspicious of a sales associate's effort to prove them wrong. The number of misinformed buyers is likely to increase with the use of Web-enabled genres because of information overload on the part of the buyers. When a buyer is in a situation of information overload, i.e., a condition in which the amount of information that warrants attention exceeds the individual's ability to process it (Schultze and Vandenbosch 1998), he/she may feel more informed and more satisfied with the information gathering activity. However, because the information available exceeds the buyer's processing capacity, he/she is incapable of separating the relevant from the irrelevant, which leads to poor comprehension and decision making (O'Reilley 1980).

Based on the above discussion, we can formulate the following hypotheses related to the use of Web-enabled genres for the communicative act of information gathering:

H1.1: When Web-enabled genres are used in information gathering, the buyer's perceived cost will be lower than when genres based on other communication media are used.

H1.2: Buyers will gather more and a greater variety of information when they rely on Web-enabled genres than they do when they rely on genres based on other communication media.

H1.3: Buyers' satisfaction with information gathering will be higher when they rely on Web-enabled genres than when they rely on genres based on other communication media.

H1.4: The sales associate satisfaction with information gathering will decline as more buyers complete their information gathering activities through Web-enabled genres.

${ }^{5}$ Information on the Web is regarded as accurate and reliable until the user finds out otherwise (Chisholm 1999; Kanell 1998). 


\subsection{Test Drive}

The purpose of a test drive is for the buyer to interact with a car. The primary participants in this communicative act are thus the buyer and the car. However, a sales associate typically accompanies the buyer on a test drive not only to control the duration and route, but also to highlight features of the car and answer the buyer's questions. The test drive thus overlaps somewhat with the communicative act of information gathering. The content of test drive genres is focused primarily on the features of the car, both in explicit as well as sensory and non-verbal terms.

Paper-based genres are not viable for this stage of the car buying process and Webenabled genres offer only a weak substitute for the face-to-face experience. This is because the tactile, experiential nature of the interaction between the car and buyer is only partially emulated in the Web-enabled genres. Appendix B summarizes the comparison between the three genre categories for the communicative act of test driving.

The face-to-face test drive is structured in the following way. The sales associate follows a protocol of preparation during which the buyer's driver's license and proof of insurance is procured. This is followed by a 10 to 15 minute test drive. The buyer is fully identified. The communication is interactive and customized to the buyer. The sales associate has the power to deny a test drive and may determine its route and duration.

The language between car and buyer/driver is non-verbal, tactile and affective. The language between sales associate and buyer that occurs during a test drive is informal and typically focused on features of the car.

In Web-enabled genres, a virtual test drive supported by virtual reality or Quicktime ${ }^{\mathrm{TM}}$ provides an unlimited, user-directed and interactive experience through makes and models. The buyer remains anonymous. Thus, the structure of the Webenabled test drive varies considerably from that in the real world.

Similarly, the language in the Web-enabled test drive genre is quite different from that in the face-to-face genre. The Web-enabled genre uses non-verbal language including flashpix, video, and images, as well as explicit, verbal language in the form of text and voice. For instance, the virtual experience is accompanied by persuasive marketing commentary, which describes what the buyer would perceive in the real world. However, the sensory nature of the interaction between the car and the driver cannot be recreated over the Web at this time.

In summary, we do not expect Web-enabled genres to have a significant impact on the communicative act of test driving but virtual test drives may help buyers narrow their car choice. This will require buyers to test drive fewer cars than they might otherwise have done. This suggests that virtual test drives speed up the car buying process as a whole and they reduce the amount of time a sales associate interacts with the car buyer. We derive the following hypotheses for the communicative act of test driving:

H2.1: Web-enabled genres used for test driving, e.g., virtual test drives, will not replace "real" test drives.

H2.2: The use of Web-enabled genres for test driving will reduce the number of real test drives that a buyer will want to make. 


\subsection{Qualification of a Buyer}

The purpose of this communicative act is for the sales associate to determine how serious the buyer is with respect to purchasing a car and, more specifically, a car from the sales associate's dealership. This assessment includes a determination of the buyer's ability to pay for the make and model of car in question. In a face to face context, the sales associate typically relies on social cues such as dress, age, ethnicity and general demeanor to make such an assessment. The associate seeks to elicit information on the customer's profession, the time frame within which they expect to make the purchasing decision, and other dealerships under consideration.

Buyer qualification can be accomplished though a variety of genres, although those based on face-to-face interaction and electronic media are the most prevalent. (The differences between the three genre categories are summarized in Appendix C.) In the case of paper-based genres, the structure of the communicative act is interactive and asynchronous and most of the interactions will be conducted through the mailing of paper forms. The language on these is formal and explicit, and the forms are likely to consist of a fair amount of legalese.

When the face-to-face genre is used for buyer qualification, the sales associates are gathering qualifying information throughout their interactions with the buyer. This starts at the initial point of contact with the buyer. Buyer qualification is done in an informal manner with the sales associate observing buyers and asking them a series of questions. The structure of face-to-face genres is thus interactive, synchronous and primarily initiated by the sales associate. The language of buyer qualification is informal and, to some extent, non-verbal.

Purchasers relying on Web-enabled genres have the option of communicating directly with dealers via e-mail, or being referred to dealers through third parties, e.g., Auto-by-tel. The e-mails typically request an appointment to test drive a car or to evaluate a trade-in car. By initiating this process through Web-enabled genres, a buyer is deemed to signal seriousness. ${ }^{6}$ Given the novelty of Web-enabled genres in the car buying process, it may be reasonable for sales associates to assume that the use of e-mail to schedule an appointment signals a customer's seriousness. With more widespread use of this genre, we would expect its value as a proxy for buyer qualification to deteriorate. For instance, buyers will schedule appointments via e-mail that they then do not keep.

Buyers can be pre-approved for credit through banks or other lending institutions. Credit applications can be made over the Web, and dealers who are strategically aligned with the lending institution at which the buyer files an application would have knowledge of the customer's ability to pay for the car.

Buyers can gain a better understanding of what constitutes a legitimate qualification procedure (i.e., what questions and information requests are reasonable) when these are published explicitly on dealers' Web sites or compiled into forms. This creates the impression that the communicative act of buyer qualification is less subjective and personal. Buyers will thus feel less vulnerable and exposed (Kanell 1998, Mahoney 1991). The formality of the language and the explicitness of information play an

\footnotetext{
${ }^{6}$ This insight was gained through personal correspondence with a sales associate in a car dealership based in a large city in the southwestern region of the U.S. (1/15/99).
} 
important role in increasing the buyer's satisfaction with the buyer qualification communicative act.

Furthermore, the asynchronously structured interaction with the dealership/sales associate implies that the buyer has time to contemplate the information that he/she is asked to provide. Thus, when Web-enabled genres are used, the buyer has more control over the timing of this communicative act than he/she does in face-to-face genres. We expect the level of satisfaction to increase more among women than among men because women feel particularly uncomfortable being questioned and pressured by sales associates who are primarily male (Mahoney 1991, Prochazka-Dahl 1997).

By making the buyer qualification procedure more explicit through Web-enabled genres, sales associates lose some of their knowledge advantage over buyers This loss of power is likely to lower sales associates' satisfaction. The use of Web-enabled genres will also force sales associates to change their work practices. In order to meet Internet users' expectations, sales associates need to respond to customers within 15 minutes (Conger and Mason 1998). There is also an increased need to manage an appointment schedule. This increased job pressure, coupled with a loss of power over the buyers, is likely to decrease sales associates' satisfaction.

The hypotheses relating to buyer qualification are:

H3.1: The use of Web-enabled genres during buyer qualification will increase buyer satisfaction.

H3.2: The use of Web-enabled genres during buyer qualification will decrease sales associates' satisfaction.

\subsection{Negotiation of Price}

The purpose of price and terms negotiation is to arrive at a mutually satisfactory deal. The minimum content of genres used in price negotiations includes offer terms and amounts, problems that the buyer might have in pursuing a purchase elsewhere (e.g., "You will not be able to get these terms at $x y z$ dealership because they are exclusive here"), and statements that describe the quality of the deal (e.g., "You really are getting a bargain here"). Whether issues concerning "hold backs," dealer incentives, manufacturer's suggested retail price (MSRP) and its components make it into the communicative act of price negotiation depends on the buyer's prior knowledge of these. Buyers, in general, distrust car dealers and have widespread beliefs that dealers withhold information about vehicle quality and potential negotiating points. The price negotiation phase of the car buying process represents a time when the stakes are high for both buyers and sales associates. It is thus also a time of tension when emotions run high.

While all three categories of genres can be used to conduct price negotiation, paperbased correspondence is infrequent for reasons similar to those discussed under the "buyer qualification" section. In the interest of space, is not discussed further here. Please refer to Appendix D for a summary of the difference between the three genre categories as they apply to price negotiation.

To help sales associates structure price negotiations in their favor when face-to-face genres are used, some car retailers train them to control the exchanges with buyers during this phase of the car buying process. They use scripts that avoid topics such as "hold backs." This implies that sales associates are better prepared with the generic 
responses required during price negotiation than the buyer is in the face-to-face environment.

Web-enabled genres provide buyers with more information about how deals are structured, what the price components are ${ }^{7}$ and how prices compare across dealerships. A buyer equipped with detailed price information can exert pressure on a sales associate to account for all price components and negotiate with respect to each (Kichen 1997). The margins that sales associates will be able to make on the sale of a car are likely to shrink as a result of the use of Web-enabled genres. Furthermore, buyers can find tips on how to negotiate with sales associates on the Web. This gives buyers a greater degree of control over price negotiation.

In the case of price negotiation, the asynchronous structure of communicative acts supported by Web-enabled genres decreases the sales associates' ability to put pressure on buyers to make their decision quickly. The use of Web-enabled genres gives buyers the opportunity to negotiate deals with multiple sales associates at the same time. Buyers therefore have more comparative information and more time to evaluate a specific deal, making them feel more in control and less pressured to close on a deal. When Web-enabled genres are used during price negotiation, the buyer controls the communicative act more than the sales associate does.

The following hypotheses summarize the effects of using Web-enabled genres during price negotiation:

H4.1: The use of Web-enabled genres during price negotiation will increase buyer satisfaction.

H4.2: The use of Web-enabled genres during price negotiation will be more controlled by the buyer than by the sales associate.

H4.3: The sales associate's satisfaction with price negotiation will decline the more negotiation is with buyers educated through Web-enabled genres.

\subsection{Finalizing Sale}

The purpose of finalizing the sale is to complete terms and all necessary paperwork, to exchange physical items such as documents of ownership, keys, and cars, and to conduct a final briefing on the features of the car. The content of this communicative act includes title and registration for any trade-ins, buyer's insurance verification and driver's license, loan documents for signatures and exchange, and various required documents about odometer readings and car condition. Face-to-face genres are more likely than other genre categories to include assurances of the quality of the deal and of the vehicle to delay the onset of buyer's remorse.

The use of paper-based genres for finalizing the sales is possible due to the physical nature of the artifacts that need to be exchanged between the buyer and the dealership, e.g., car titles, checks and keys. The electronic nature of Web-enabled genres does not support the transfer of physical artifacts and is, therefore, of use only in some aspects of the sales finalization stage of the car buying process.

${ }^{7}$ Examples of web sites with information about price components: www.uniprimeinc.com, www.carpoint.com, www.edmunds.com, www.intellichoice.com; www.autoreach.com. 
The structure of sales finalization using face-to-face genres is determined by the finance person responsible for ensuring the completion of the appropriate documents. The role of the sales associate is one of reminding the buyer of the quality of the deal and of the vehicle. The language is formal and pertains mainly to the documents involved.

The major difference between the face-to-face and Web-enabled genres is the asynchronous structure of the Web-enabled communicative act. This implies that the elapsed time will be longer than if face-to-face genres are used, while applied time should be the same as in face-to-face genres. Applied time may, however, be shorter because electronic forms and document templates may be used to standardize the information exchange and thereby streamline the activities that make up the sales finalization stage of the car buying process.

Most buyers find parting with their money, committing to new car payments, and having their financial status discussed an uncomfortable experience (Chisholm 1999). As a result, any disintermediation that renders the exchanges required for the sales finalization less personal is expected to increase buyer satisfaction, especially among women.

The hypotheses generated from this discussion are:

H5.1: The use of Web-enabled genres during finalizing a sale will increase buyer satisfaction, especially among women customers.

H5.2: The use of Web-enabled genres during finalizing a sale will increase elapsed time of the communicative act while applied time will be no longer and may be shorter.

\subsection{Overall Impact on the Car Buying Process}

The increased satisfaction among car buyers that accompanies the use of Web-enabled genres is based on more cost-effective access to information and the ability to access more information about cars and about the price components. By becoming a more informed customer, car buyers can exercise more control over the car buying process. Furthermore, the buyer's ability to negotiate deals with multiple dealerships at the same time and thereby find the best deal, increases buyer satisfaction. The disintermediating and depersonalizing roles Web-enabled genres play in the car buying process are particularly valued by women customers, who are frequently treated with condescension by primarily male sales associates.

The asynchronous nature of Web-enabled communication suggests that there will be delays within communicative acts and between the different communicative acts. This increases the elapsed time of the entire car buying process. However, time saved by fewer test drives and more streamlined procedures during sales finalization is expected to reduce or keep constant the actual applied time it takes to complete the car buying process.

Car sales associates are under siege and there is pressure from car buyers and information providers to change their practices (Llosa and Lee 1998). For instance, with the increased use of Web-enabled genres, sales associates will have to surf the Web, use e-mail and schedule and keep appointments. Sales associates' satisfaction with their jobs is expected to decrease as more buyers become more knowledgeable about vehicles and 
prices through Web-enabled genres. Armed with more information, buyers can negotiate more aggressively and have more control over the communicative acts. Influencing buyers' decisions, especially when buyers are misinformed, becomes more of a challenge. The asynchronous nature of Web-enabled genres also decreases the sales associate's ability to put pressure on the buyer to make decisions quickly.

The following hypotheses summarize this discussion of the effects of Web-enabled genres on the car buying process as a whole.

H6.1: The use of Web-enabled genres will increase buyer satisfaction for the overall car buying process, especially for women customers.

H6.2: The use of Web-enabled genres during the purchase of a car will increase elapsed time of the process while actual applied time will be no longer and may be shorter.

H6.3: The use of Web-enabled genres will decrease sales associates' satisfaction with the overall car buying process.

\section{Conclusion}

This paper contributes to research on electronic commerce by developing a framework that combines genre theory and business process thinking. This is a general framework that can be applied to business processes other than the car buying process, on which we focus here. This paper generates a set of testable hypotheses that are conducive for future empirical research on the effect of the Web on the car buying process.

In its current hypothesis formulation phase, this research also contributes to practice by developing a framework for understanding the nature of the car buying process and the changes on this process by Web-enabled genres. This understanding is expected to help car dealers plan for the impacts of electronic commerce on their business by adapting, among other things, their hiring and training practices. We also anticipate that this framework will serve as a map for dealers who want to identify how they can differentiate themselves from other dealerships by adding value to a process that is becoming increasingly generic through the use of Web-enabled genres.

\section{References}

Abrams, M. H. A Glossary of Literary Terms, $5^{\text {th }}$ ed. Orlando, FL: Holt, Rinehart and Winston, 1988.

Bazerman, C. "Systems of Genres and the Enactment of Social Intentions," in Genre and the New Rhetoric., A. Freedman and P. Medway, (eds.). London: Taylor and Francis, 1995, pp. 79101.

Business Wire. "Auto-By-Tel First Company to Complete Internet Car Buying Equation with Online After Market Sales." February 1, 1998.

Chisholm, P., and Bergman, B. "Personal Finance: The Tough Lot of a Car Buyer," Maclean's, January 11, 1999, p. 49.

Conger, S., and Mason, R. O. Planning and Designing Effective Web Sites. Boston: Course Technology, Inc., 1998. 
Crowston, K., and Williams, M. "The Effects of Linking on Genres of Web Documents," Proceedings of the Thirty-second Hawaii International Conference on System Sciences: Minitrack on Genre in Digital Documents, 1999.

Daft, R. L., and Lengel, R. H. "Organizational Information Requirements, Media Richness and Structural Design," Management Science (32:5), 1986, pp. 554-571.

Dunnan, N. "Financial Fix: What'sYyour Investing Goal?" Enter Magazine, April 1, 1998.

Essence. "Road Scholars" (28), November 1997, pp 160-165.

Llosa, L. F., and Lee, E. Y-J. "Car Buyer's Guide 1998: Sticker Shock! For the First Time in 20 Years, Prices are Falling-Yes, Falling. Here's How to Get the Best Deals on New Cars, Vans and Sport Utilities," Money, January 1998, p. 124.

Girishankar, S. "E-Commerce: Virtual Markets Create New Roles For Distributors," InternetWeek, April 6, 1998.

Griffith, T. L., and Northcraft, G. B. "Distinguishing between the Forest and the Trees: Media, Features, and Methodology in Electronic Communication Research," Organization Science (5:2), 1994, pp. 272-85.

Kambil, A., and van Heck, E. "Reengineering the Dutch Flower Auctions: A Framework for Analyzing Exchange Organizations," Information Systems Research (9:1), 1998, pp. 1-19.

Kanell, M. E. "AutoConnect Takes to the Net: Web Site Aims to Simplify Sales," The Atlanta Journal and Constitution, May 1998, p. B08.

Kichen, S. "Cruising the Internet," Forbes Magazine, March 1997, pp 198.

Mahony, R. "Car Buying: Why Women Get a Lemon of a Deal. (Discrimination in Automobile Selling)," Ms. Magazine (1:4), January-February 1991, p 86-88.

Maugh III, T. H. "Doctors Interrupt Too Quickly, Listen Too Little," Los Angeles Times Home Edition Health, January 25, 1999, p 4.

Miller, C. "Genre as Social Action,” Quarterly Journal of Speech (70), 1984, pp 151-176.

Orlikowski, W., and Yates, J. "Genre Repertoire: The Structuring of Communicative Practices in Organizations," Administrative Science Quarterly (39), 1994, pp. 541-574.

O'Reilly, C. A. "Individuals and Information Overload in Organizations: Is More Necessarily Better?" Academy of Management Journal (23), 1980, pp. 684-696.

Prochazka-Dahl, L. "They Really Are Different (Selling Cars to Women)," Ward's Dealer Business, February 1997, p. 31.

Schultze, U., and Vandenbosch, B. "Information Overload in a Groupware Environment: Now You See It, Now You Don't," Journal of Organizational Computing and Electronic Commerce (8:2), 1998, pp.127-48.

Shepherd, M., and Watters, C. "The Functionality Attributes of Cybergenres," Proceedings of the Thirty-second Hawaii International Conference on System Sciences: Minitrack on Genre in Digital Documents, 1999.

Yates, J., and Orlikowski, W. "Genres of Organizational Communications: A Structurational Approach to Studying Communication and Media," Academy of Management Review (17:2), 1992, pp. 229-326.

\section{About the Authors}

Sue A. Conger has a Ph.D. from New York University in computer information systems. She has written two books, Planning and Designing Effective Web Sites (with Richard O. Mason) in 1998, and The New Software Engineering in 1994. Sue's research interests are electronic commerce, computer ethics, and software engineering. She is currently on the faculty at the Edwin L. Cox School of Business at Southern Methodist University in Dallas, Texas. She can be reached via e-mail at SConger@aol.com. 
Ulrike Schultze is Assistant Professor in Information Systems and Operations Management at Southern Methodist University. Her research focuses on knowledge work, particularly the social processes of creating and using information in organizations. Ulrike has written on hard and soft information genres, information overload, knowledge management and the work practices that make up knowledge work. Her recent projects are in the areas of electronic commerce and virtual organizations. She received her bachelor's and master's degree in Management Information Systems from the University of the Witwatersrand in Johannesburg, South Africa, and her Ph.D. in MIS from Case Western Reserve University, Cleveland, Ohio. She can be reached at uschultz@mail.cox.smu.edu. 


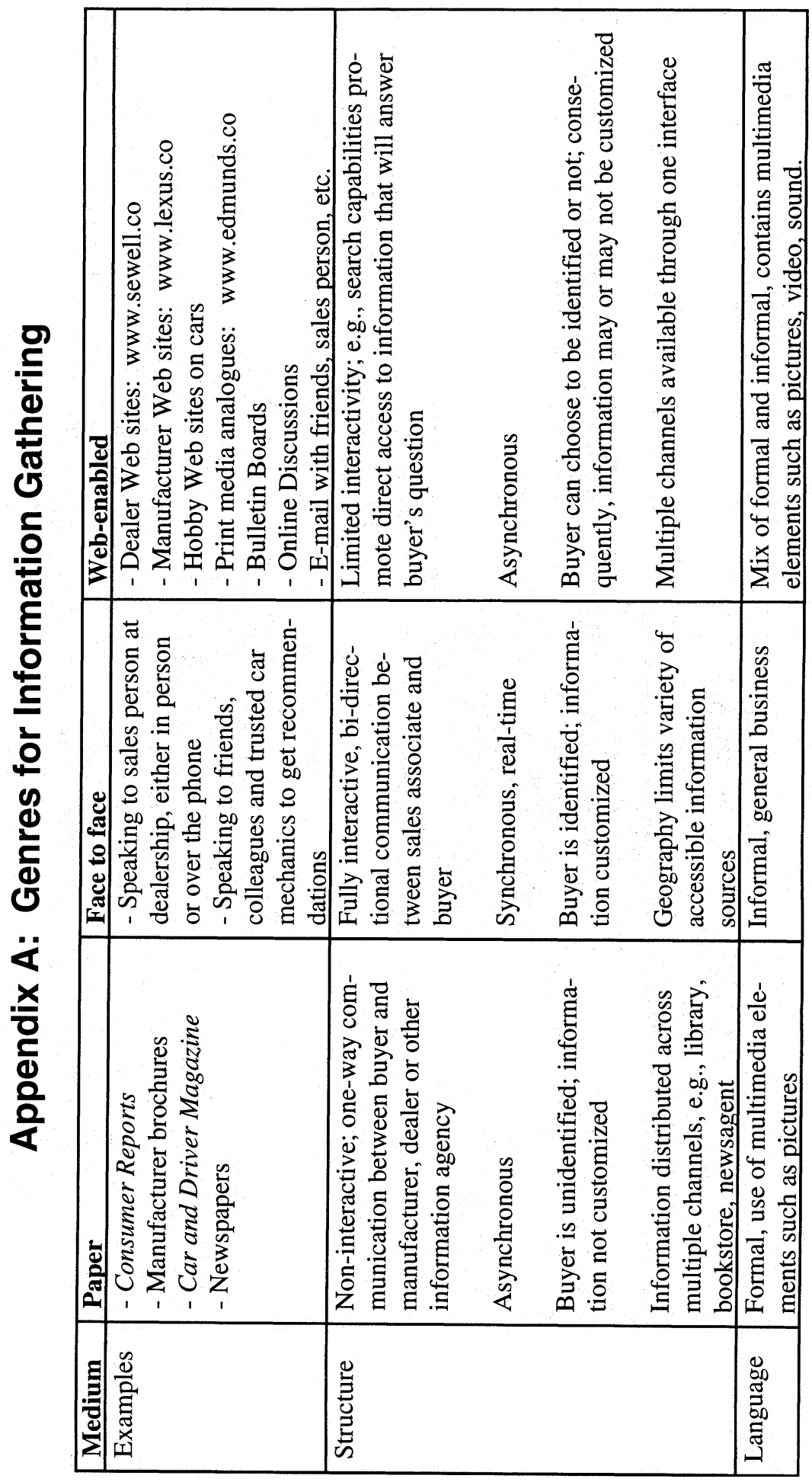




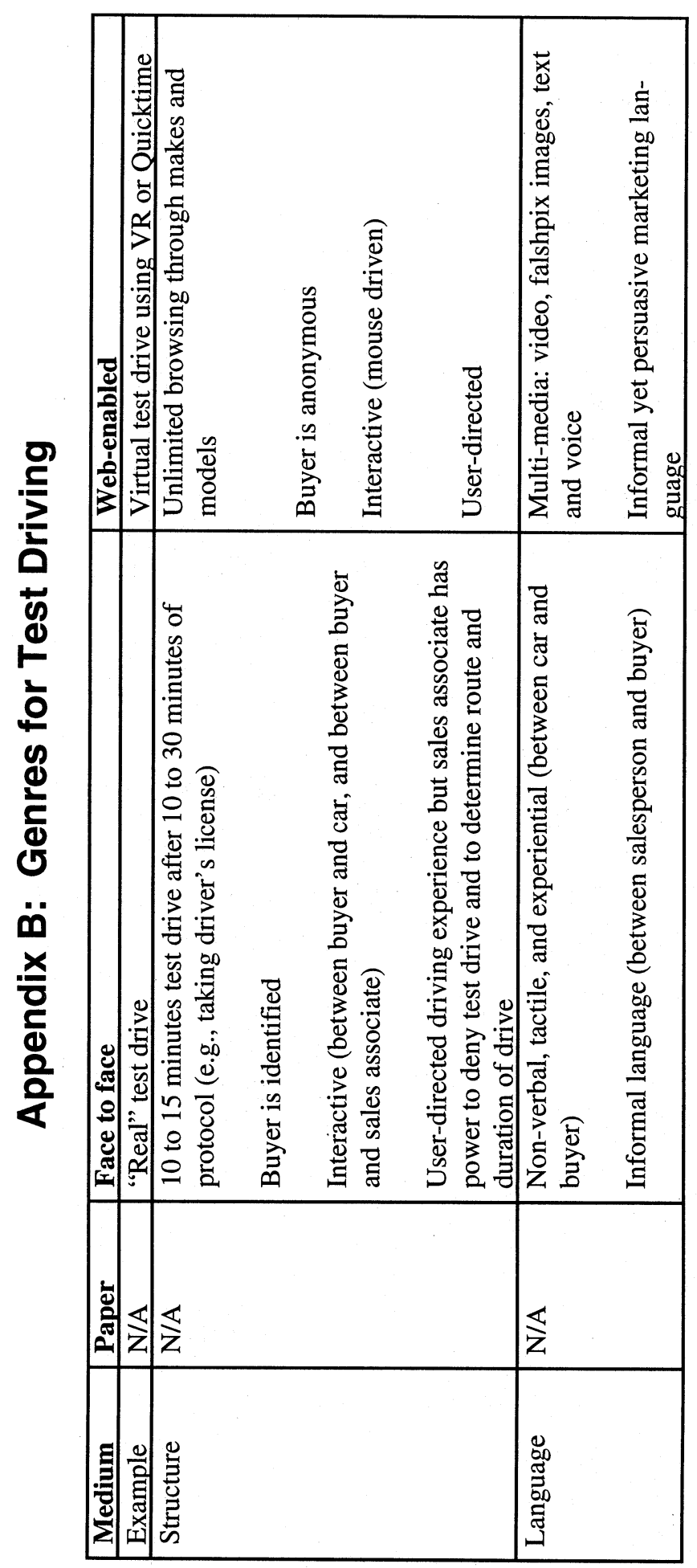




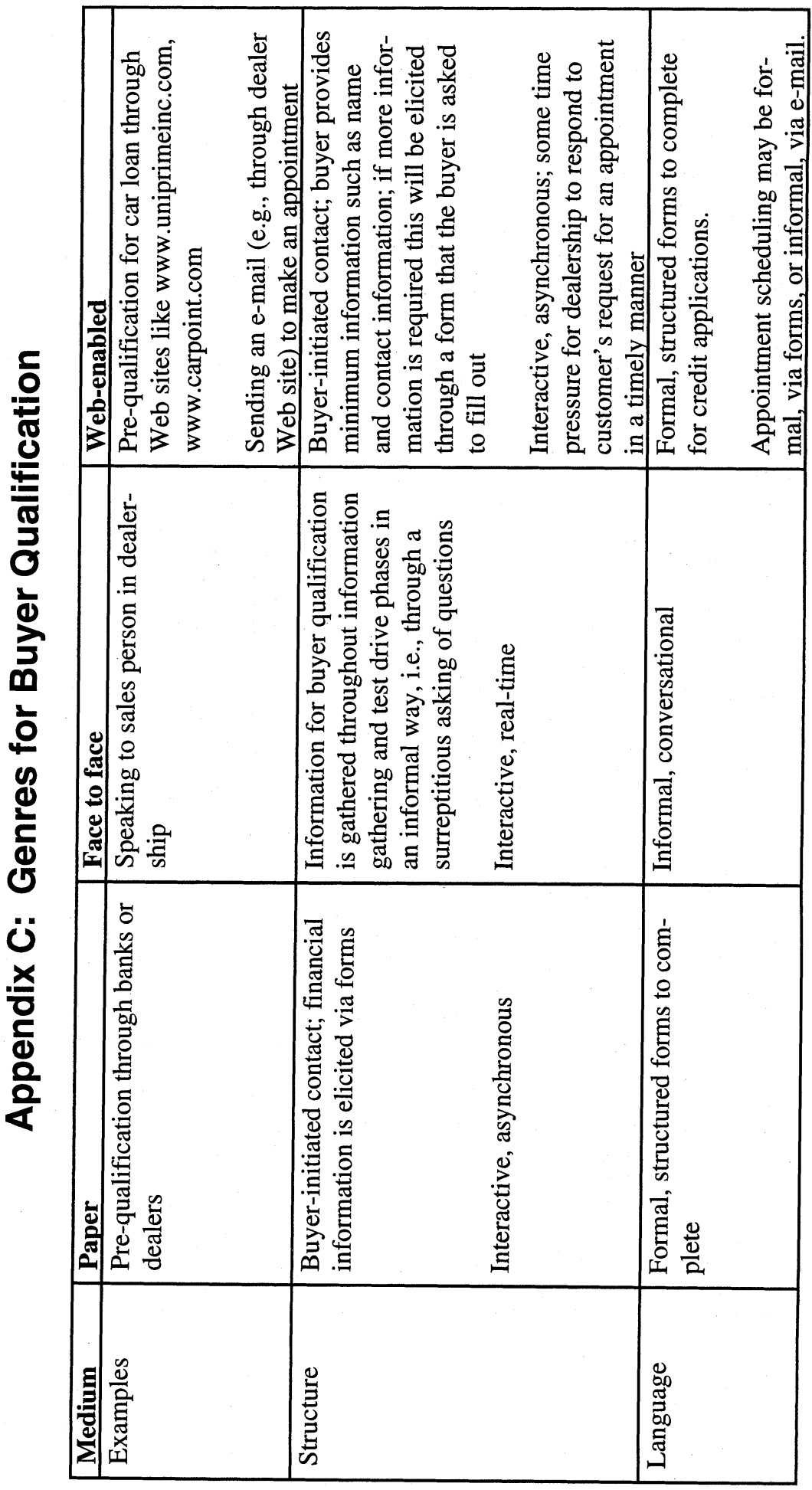




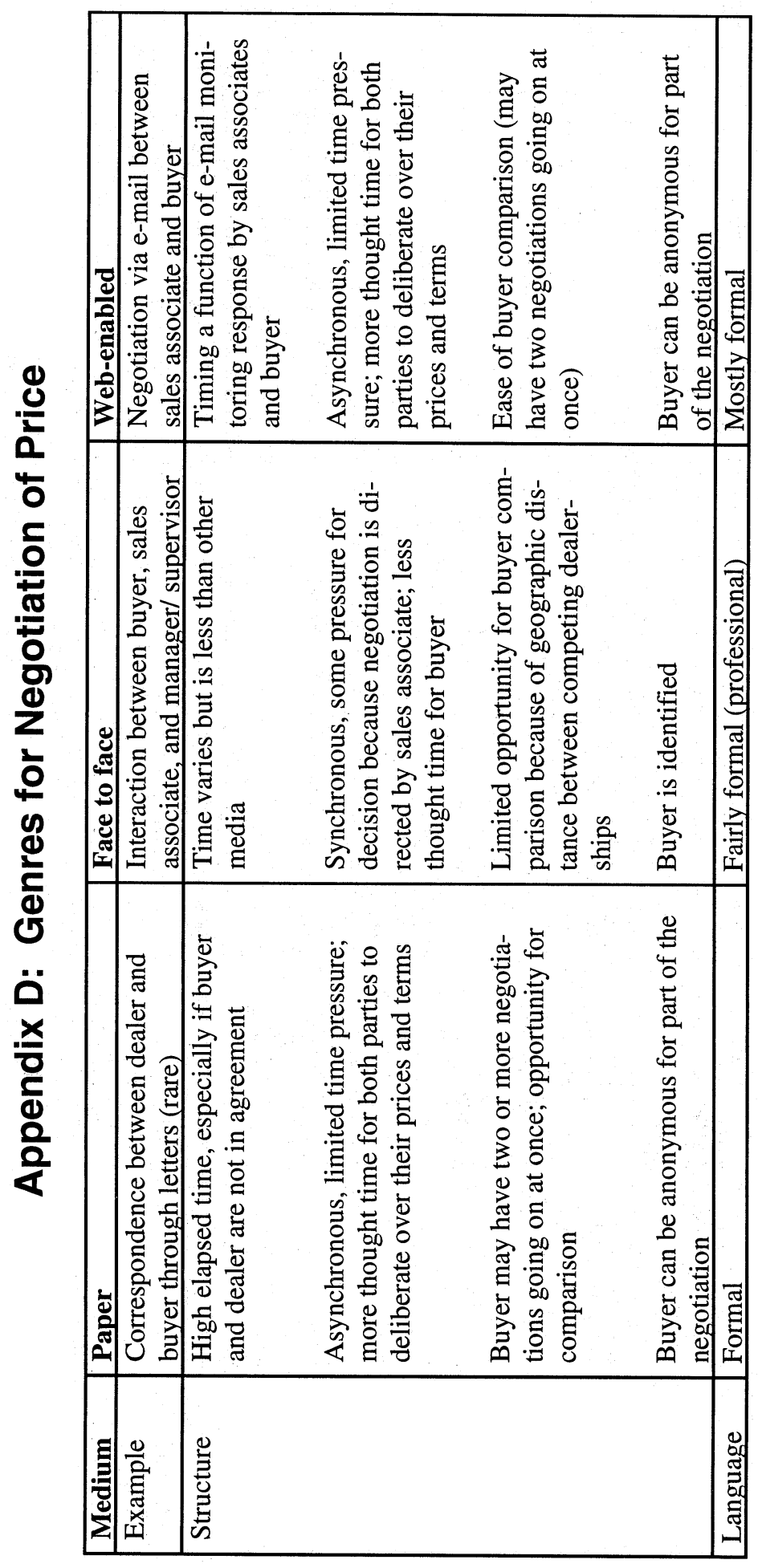




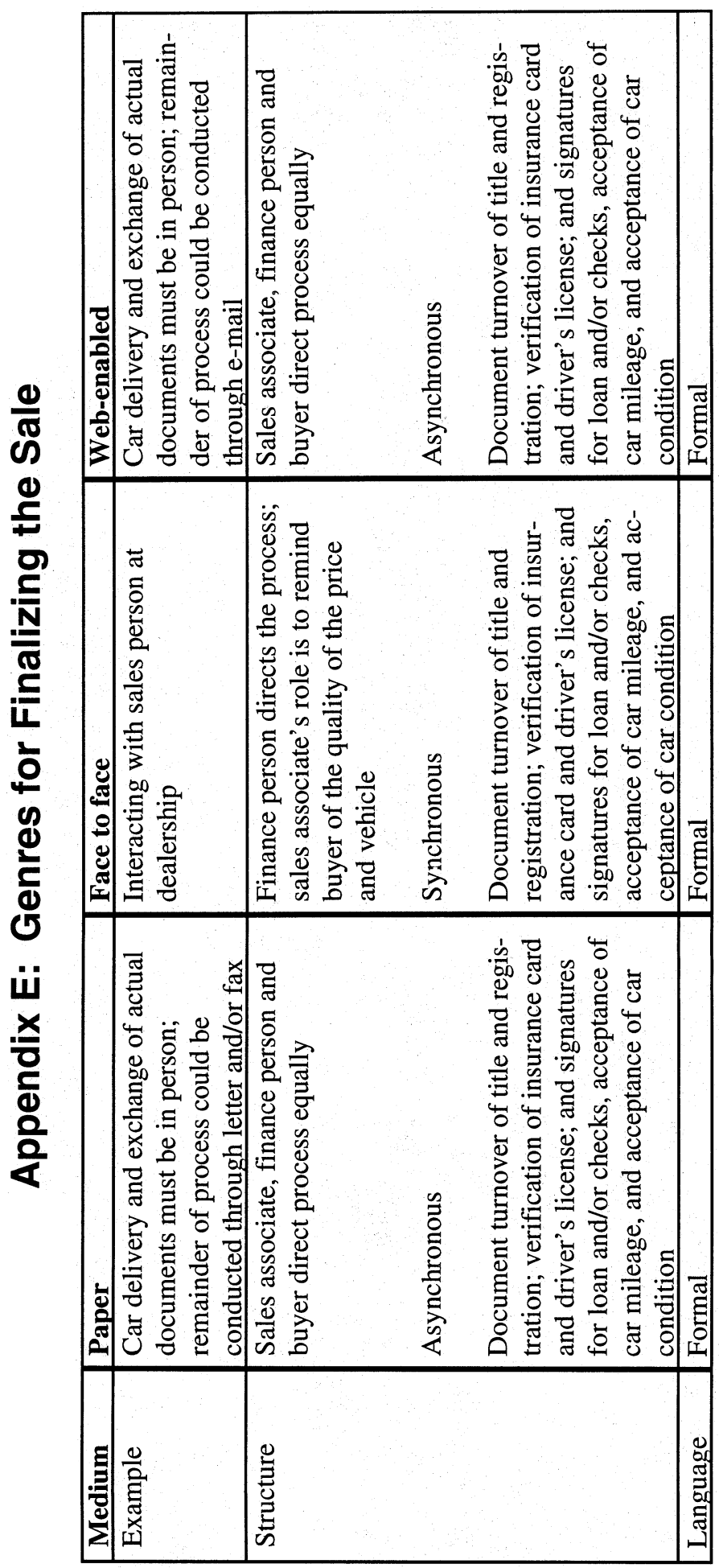

